\title{
The effect of specific gravity and size on the mean time of retention of inert particles in the alimentary tract of the cow
}

\author{
By R. C. CAMPLING AND M. FREER* \\ National Institute for Research in Dairying, Shinfield, Reading \\ (Received 22 December 1961-Revised 2 April I962)
}

The voluntary intake of a roughage by a cow is closely related to the mean time of retention in the alimentary tract of the residues derived from the roughage (Campling, Freer \& Balch, 196r). The physical characteristics of food particles as they pass through the animal may be important in determining their time of retention. The effects of several physical characteristics have been studied by previous workers using inert particles of known size and specific gravity. For example, Hoelzel (r930) used rubber, cottonseed, glass beads and several metals in a human subject, and in cattle King \& Moore (1957) used various plastics.

King \& Moore (1957) observed that, of the plastic particles examined, those with a sp. gr. of $\mathrm{I} \cdot 20$ and between 20 and $30 \mathrm{~mm}^{3}$ in size were retained for the shortest time in the bovine alimentary tract. In our first experiment we have examined the effect of the specific gravity of inert particles on their mean retention time in the alimentary tract of the cow, and have given particular attention to the relative time the particles were retained in the reticulo-rumen and in the remainder of the alimentary tract. In this experiment the cows received diets of oat straw or hay and the preliminary results have been briefly reported (Campling \& Freer, 1960). In a second experiment we have extended this examination to cows given diets of hay, dried grass or concentrates. The effect of the size of inert particles on their mean time of retention was examined in a third experiment.

The use of easily distinguishable inert particles to measure the time of retention of food in the alimentary tract would provide a less laborious alternative to the present method (Balch, 1950) in which stained food residues are counted in the faeces. Ewing \& Smith (I9I7) and Moore \& Winter (1934) used rubber particles for this purpose, and during the past 2 years we have on numerous occasions compared the time of retention of stained food in the alimentary tract with that of polystyrene particles (Expt 4).

\section{EXPERIMENTAL}

Seven adult non-lactating, non-pregnant cows, five Shorthorn and two Friesian, were used in the four experiments. Each cow was fitted with a permanent rumen fistula which was closed by means of a rubber cannula and bung. The cows were kept in individual standings in a metabolism house. Water and salt licks containing trace

* Present address: C.S.I.R.O., Division of Plant Industry, Canberra, Australia. 
minerals were accessible at all times, except in Expt $\mathrm{I}$ when water was available for $4 \frac{1}{2} \mathrm{~h}$ each day from the beginning of a meal. A daily supplement of $40 \mathrm{~g}$ of a mineral mixture (Churn 105, British Glues \& Chemicals Ltd) and a weekly supplement of vitamins A and D (Drivite, Boots Pure Drug Company Ltd) were also given to each cow. In all the experiments the complete daily allowance of food was offered in one meal, for $4^{\frac{1}{2}}-5 \mathrm{~h}$, and the uneaten food remaining was removed and weighed. The cows were kept on a diet for at least 3 weeks before inert particles were given. Faeces were collected by means of the harness and bags described by Balch, Bartlett \& Johnson (I95 I), the bags being changed at intervals of about $6 \mathrm{~h}$, and the collection continued until no inert particles were found in the faeces. At each collection $70 \%$ of the faeces was washed through a sieve (mesh no. Io, aperture $1676 \mu$ ) and the inert particles were recovered and counted.

\section{Interpretation of results}

The mean time of retention of the inert particles was expressed in the way suggested by Castle (1956) for the retention of stained food in the alimentary tract. The results obtained for inert particles placed in the rumen gave a measure of the time particles were retained in the whole gut, the results for particles placed in the abomasum showed the mean time of retention in the hind gut; the difference between these two values represented the mean time of retention in the reticulo-rumen. It was assumed that the retention time of inert particles in the hind gut is the same whether particles are placed directly into the abomasum immediately before food is given or whether they reach the abomasum from the reticulo-rumen. This assumption is supported by the observation of Balch (I95) that there is close agreement between the initial appearance of stained particles from the food and the clearance of stained particles inserted in the abomasum.

\section{Materials used as inert particles}

Many materials were investigated for use as inert materials, among them rubber, and several plastics including polyethylene, polypropylene, polystyrene, polycarbonate, methyl methacrylate, cellulose acetate and polyvinyl chloride. Rubber was most used in the experiments reported below because it changed little in its passage through the gut. We obtained through the courtesy of the National Rubber Development Board and the Avon India Rubber Co. a series of specially prepared rods of coloured rubber of different sp. gr. ranging from I.02 to I ${ }^{\circ}$. The rods of $4 \cdot 0 \mathrm{~mm}$ diameter were cut into particles of various sizes. Tests showed that the suspension of rubber in the ventral sac of the reticulo-rumen for $\mathrm{I} 62 \mathrm{~h}$ resulted in very little $(+\mathrm{r} \%)$ change in weight of the rubber. Although rubber particles can be broken during rumination, particles of about $13 \mathrm{~mm}^{3}$ in size were affected relatively little, perhaps because of their size and resilience.

Of the plastics, it was thought that polystyrene would be particularly useful as an indicator of the mean retention time of particles of digesta, because this material has a sp. gr. of $\mathrm{I} .04$ which is similar to that of digesta in the reticulo-rumen of hay-fed cows (Balch \& Kelly, 1950). Also, uniform small (20 mg) particles are available com- 
mercially (The General Chemical \& Pharmaceutical Co. Ltd) in several different colours. Polystyrene particles were subject to some physical breakdown during rumination. Polycarbonate, methyl methacrylate and cellulose acetate particles are much harder, but all three have a sp. gr. of about $\mathrm{x} \cdot \mathbf{2}$. Several trials were made with particles of different sizes made from methyl methacrylate. Polyethylene and polypropylene have a sp. gr. less than $\mathrm{r}$, and particles made from these materials may remain in the reticulo-rumen for several weeks. Also many polyethylene particles are soft and are often broken during rumination and for these reasons were seldom used in our experiments.

\section{Expt I. Effect of specific gravity on the mean retention time of inert particles in cows}

Four Shorthorn cows were used. Cows $\mathrm{E}$ and $\mathrm{H}$ were offered, and ate, a daily ration of $\mathrm{Io} \mathrm{lb}$ hay and cows $\mathrm{F}$ and $\mathrm{G}$ were offered io $\mathrm{lb}$ oat straw and ate about 8.7 and $7.3 \mathrm{lb}$ respectively. The chemical composition of these foods is given in Table $\mathrm{I}$. Immediately before feeding, 300 rubber particles of about $13 \mathrm{~mm}^{3}$ in size, of each of the specific gravities $\mathrm{I} \cdot 02, \mathrm{I} \cdot 06, \mathrm{I} \cdot \mathrm{I} 2$ and $\mathrm{I} \cdot 2 \mathrm{I}$, and of different colours, were put directly

Table I. Expts I and 2. Chemical composition of foods

\begin{tabular}{|c|c|c|c|c|c|c|c|}
\hline $\begin{array}{c}\text { Expt } \\
\text { no. }\end{array}$ & Food & $\begin{array}{c}\text { Dry } \\
\text { matter } \\
(\%)\end{array}$ & $\begin{array}{c}\text { Crude } \\
\text { protein }\end{array}$ & $\begin{array}{l}\text { Ether } \\
\text { extract } \\
\text { As pe }\end{array}$ & $\begin{array}{l}\text { Crude } \\
\text { fibre } \\
\text { tage of }\end{array}$ & $\begin{array}{l}\text { Nitrogen-free } \\
\text { extract } \\
\text { y matter }\end{array}$ & Ash \\
\hline $\mathbf{I}$ & $\begin{array}{l}\text { Hay } \\
\text { Oat straw }\end{array}$ & $\begin{array}{l}83^{\circ} \circ \\
84^{\circ} \cdot 6\end{array}$ & $\begin{array}{l}8 \cdot 7 \\
2 \cdot 9\end{array}$ & $\begin{array}{l}x \cdot 8 \\
2 \cdot 2\end{array}$ & $\begin{array}{l}3 \mathrm{I} \cdot \mathrm{I} \\
40 \cdot 6\end{array}$ & $\begin{array}{l}52 \cdot 1 \\
48 \cdot 9\end{array}$ & $\begin{array}{l}6.3 \\
5.4\end{array}$ \\
\hline 2 & $\begin{array}{l}\text { Hay } \\
\text { Dried grass } \\
\text { Concentrates }\end{array}$ & $\begin{array}{l}83 \cdot 8 \\
84 \cdot 4 \\
87 \cdot 0\end{array}$ & $\begin{array}{r}8 \cdot 4 \\
19 \cdot 6 \\
19 \cdot 8\end{array}$ & $\begin{array}{l}4 \cdot 2 \\
2 \cdot 5 \\
3 \cdot 2\end{array}$ & $\begin{array}{r}33.2 \\
18.6 \\
6.4\end{array}$ & $\begin{array}{l}46 \cdot 3 \\
45 \cdot 3 \\
63 \cdot 2\end{array}$ & $\begin{array}{r}7 \cdot 9 \\
13 \cdot 9 \\
7 \cdot 5\end{array}$ \\
\hline
\end{tabular}

into the rumen (through the fistula) at the point where the cardia opens. Simultaneously, about 100 particles of each specific gravity, and of colours different from those of the particles placed in the rumen, were introduced into the abomasum, in 200-300 $\mathrm{ml}$ warm water, by means of a stomach tube and pump. The exact number of particles passing into the abomasum was determined after the pump and stomach tube had been rinsed. The particles were recovered from the faeces as described above and the mean retention times calculated. On the day that inert particles were placed in the cows $4 \%$ of the daily intake of food was stained with magenta and the mean retention time of the stained particles in the alimentary tract was measured in the way described by Campling et al. (196r).

\section{Expt 2. Effect of specific gravity on the time of retention of rubber particles in cows given hay, dried grass or concentrates}

Two Friesian cows (A and B) and one Shorthorn cow (C) were used in a $3 \times 3$ Latin square experimental design to study the effect of the specific gravity of particles on their retention time in cows receiving three markedly different foods, hay, dried grass 
or concentrates. The chemical composition of each food is shown in Table I. The concentrates were in the form of dairy cubes and consisted of barley 17 , maize 20 , wheat bran 20, decorticated groundnut meal I $_{5}$, copra cake Io, palm-kernel cake 5 , molasses 10 , dicalcium phosphate $I$, calcium carbonate $I$, and salt $\mathrm{I} \%$, with $5 \times 10^{6}$ i.u. vitamin $A$ and $I \times I 0^{6}$ i.u. vitamin $D$ added per ton. The cows were offered as much food as they would consume in a 5 h period each day; the amounts consumed are shown in Table 2.

Immediately before feeding, coloured rubber particles of sp. gr. I·02, I·06, I·I2, $\mathrm{I} \cdot 2 \mathrm{I}$ and $\mathrm{I} \cdot 40$ and about $\mathrm{I} 3 \mathrm{~mm}^{3}$ in size were introduced into the rumen and abomasum simultaneously. The procedure was as in Expt $\mathrm{I}$ and the mean retention times of the particles and of stained food were again measured.

\section{Expt 3. Effect of size of particles on the time of retention in cows}

The experiment consisted of two parts. In part $\mathbf{I}$, three sizes of plastic balls made from methyl methacrylate (sp. gr. I·20) were given to the seven cows receiving a variety of roughage rations listed in Table 4 . On occasions when urea was given it was infused into the rumen in $20 \mathrm{lb}$ water. Three hundred balls of each of the diameters, $4.8,4^{\circ} \circ$ and $3.2 \mathrm{~mm}$, were introduced into the rumen of each cow immediately before feeding. Each size of particle was distinctively coloured. The particles were recovered from the faeces and the mean retention time was calculated in the usual way.

In the second part of the experiment two sizes of rubber particles, 20 and $13 \mathrm{~mm}^{3}$, were prepared from coloured rubber rod of each of three sp. gr., I·02, I I 12 and $I \cdot 2 \mathrm{I}$. Three hundred particles of each size and specific gravity were introduced into the rumen of cows $E$ and $F$ immediately before feeding. The daily intake of food by cow $\mathrm{E}$ was $24^{\circ} \mathrm{I} \mathrm{lb}$ hay and by cow F $8.8 \mathrm{lb}$ oat straw. Particles were recovered from the faeces and the mean retention time was calculated.

\section{Expt 4. Comparison of the times of retention in cows of polystyrene particles and stained food}

On thirty-six separate occasions, 300 particles of polystyrene of sp. gr. I.04 and $20 \mathrm{mg}$ in weight were introduced into the rumen simultaneously with stained foods given by mouth. The polystyrene particles were recovered from the faeces and counted and the mean retention time was calculated. The mean time of retention of stained food in the alimentary tract of the cow was measured as in Expt $\mathbf{I}$.

\section{RESULTS}

Expts I and 2. Effect of specific gravity on the mean retention time of inert particles in cows

Expt 1. The results are presented in Table 2 and the mean values are shown graphically in Fig. I. In all four cows the shortest mean time of retention in the whole gut was found with particles of sp. gr. I.I2 and the longest time with particles of sp. gr. I·02. Mean retention time in the reticulo-rumen fell with increasing specific gravity from $73 \mathrm{~h}$, on average, for particles of sp. gr. $\mathrm{r} \cdot 02$ to $28 \mathrm{~h}$, on average, for 
particles of sp. gr. I.2I. Mean retention time in the hind gut, in contrast, was directly related to specific gravity, increasing, on average, from 29 to $5^{2} \mathrm{~h}$ as the sp. gr. of the particles increased from $\mathrm{I} \cdot 02$ to $\mathrm{I} \cdot 2 \mathrm{I}$.

Table 2. Expt 1 . Effect of specific gravity on the mean time of retention of rubber particles in the whole gut, reticulo-rumen and hind gut of cows given hay or oat straw

\begin{tabular}{|c|c|c|c|c|c|c|c|c|c|c|c|c|c|c|}
\hline \multirow{3}{*}{\multicolumn{2}{|c|}{$\begin{array}{c}\text { Daily intake } \\
\text { of food }\end{array}$}} & \multicolumn{12}{|c|}{ sp. gr. of particles } & \multirow{3}{*}{$\begin{array}{l}\text { Mean } \\
\text { retention } \\
\text { time of } \\
\text { stained } \\
\text { food in } \\
\text { whole } \\
\text { gut } \\
\text { (h) }\end{array}$} \\
\hline & & \multicolumn{4}{|c|}{ Whole gut* } & \multicolumn{4}{|c|}{ Reticulo-rumen* } & \multicolumn{4}{|c|}{ Hind gut* } & \\
\hline & & $1 \cdot 02$ & $\mathrm{I} \cdot 06$ & $I \cdot 12$ & $I \cdot 21$ & $\begin{array}{r}\text { I.02 } \\
\text { Mean }\end{array}$ & $\begin{array}{l}x \cdot 06 \\
\text { etenti }\end{array}$ & $\begin{array}{l}I \cdot I 2 \\
\text { a time }\end{array}$ & (h) & $\mathrm{I} \cdot 02$ & $\mathrm{r} \cdot 06$ & $I \cdot 12$ & $I \cdot 2 I$ & \\
\hline $\mathrm{E}$ & ro lb hay & 79 & $5^{6}$ & 56 & 69 & 55 & 35 & 23 & 22 & 24 & 21 & 32 & 47 & 76 \\
\hline $\mathbf{F}$ & 8.7 lb straw & 104 & 90 & 75 & 77 & 68 & 57 & 37 & I8 & 35 & 35 & 39 & $5^{8}$ & 93 \\
\hline $\mathbf{G}$ & $7 \cdot 3 \mathrm{lb}$ straw & II & 98 & 84 & 90 & 85 & 57 & 39 & 29 & 34 & 42 & 46 & $6 I$ & 106 \\
\hline $\mathbf{H}$ & ro lb hay & 107 & 82 & 79 & 83 & 84 & 56 & 44 & 42 & 23 & 26 & 34 & $4 I$ & 93 \\
\hline
\end{tabular}

* For calculation of retention times in various parts of the gut, see p. 508 .

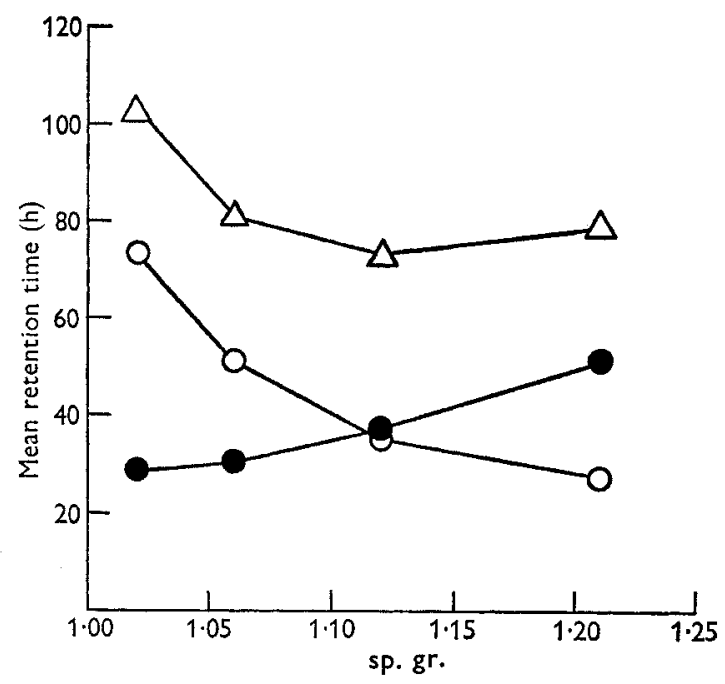

Fig. I. Expt I. Mean effect, in four cows, of the specific gravity of rubber particles on their mean retention time in the reticulo-rumen $(\circ-0)$, hind gut $(\bullet-\bullet)$ and whole gut $(\Delta-\Delta)$.

The differences found between cows in the mean retention time of inert particles were due both to food and to individual differences and followed closely the differences observed between cows in the mean retention time of stained foods. With cow $\mathrm{H}$ the mean retention time of inert particles in the whole gut was unusually long with a diet of hay, apparently entirely because of the time spent by the particles in the reticulorumen. In all the cows, stained hay was retained in the whole gut for a mean time similar to that of an inert particle having a sp. gr. between $\mathrm{r} \cdot 02$ and $\mathrm{I} \cdot 06$.

Expt 2. The results are presented in Table 3 and the mean values for each food are shown in Fig. 2. In calculating these means, the mean retention times of particles of 


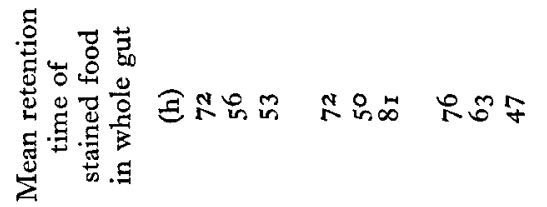

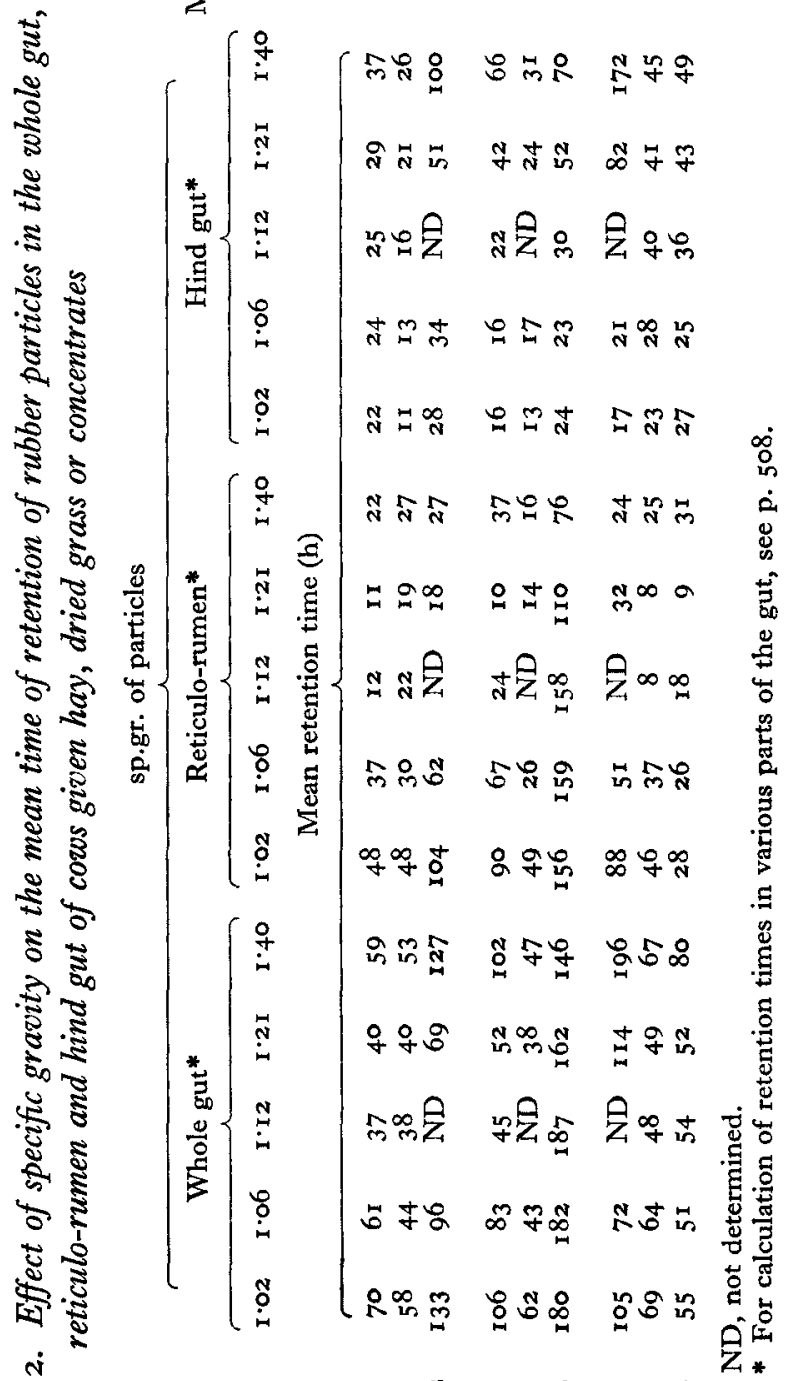

完

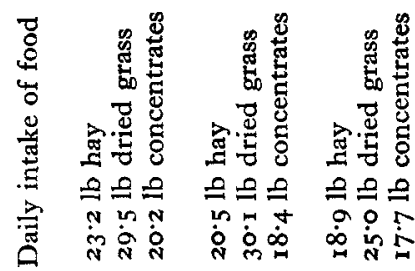

हैं 
sp. gr. $I \cdot I 2$ in the first collection period were estimated by interpolation from the results for the other particles for the individual cows. The results of this experiment confirm and extend those of Expt $\mathrm{I}$. With diets of dried grass or hay the mean retention time in the whole gut fell to a minimum value with particles of $\mathrm{sp}$. gr. $1 \cdot 12$, but with a diet of concentrates alone this value occurred with particles of sp. gr. I·2I.

The mean retention time of inert particles in the reticulo-rumen was again inversely related to $\mathrm{sp}$. gr. in the range $\mathrm{I} \cdot \mathrm{O} 2 \mathrm{-I} \cdot 2 \mathrm{I}$, but it was apparent, with diets of hay or dried grass at least, that particles of sp. gr. $1 \cdot 40$ were retained in this organ longer than those of sp. gr. I.2r. Mean retention time in the hind gut was directly related to specific gravity throughout the range $I \cdot 02-I \cdot 40$.

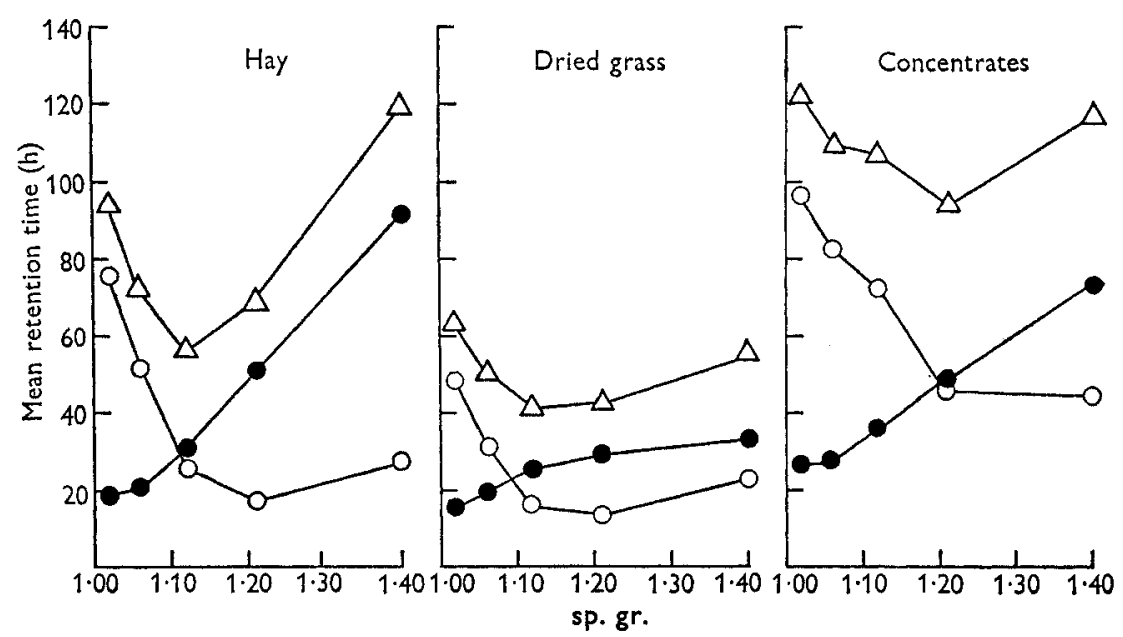

Fig. 2. Expt 2. Mean effect, in three cows each receiving three different feeds, of the specific gravity of rubber particles on their mean retention time in the reticulo-rumen $(\circ-0)$, hind gut $(\bullet)$ and whole gut $(\Delta-\Delta)$.

The mean retention times of inert particles of each specific gravity were shorter with a diet of dried grass than with a diet of hay. With both diets there was, however, relatively little difference between the three cows in the effect of specific gravity on the mean retention time of particles in the reticulo-rumen. The largest differences occurred in the hind gut, where the times of retention of inert particles in cow $\mathrm{C}$ were on average longer, and were more sensitive to changes in specific gravity, than in the other two cows.

With a diet of concentrates alone, there were extremely large differences between the three cows in the mean retention time of all particles in the whole gut. These differences resulted almost entirely from individual differences in the time spent in the reticulo-rumen, which ranged from $9-3 \mathrm{I} h$ in cow $\mathrm{C}$ to $76-\mathrm{I} 59 \mathrm{~h}$ in cow $\mathrm{B}$. Although, on average for all three cows when receiving concentrates, the mean retention time in this organ of particles of sp. gr. $I * 40$ was no longer than that of particles of sp. gr. $I \cdot 2 I$, the mean retention time was longer in cows $\mathrm{A}$ and $\mathrm{C}$, as it was in all cows with diets of hay or dried grass. 
Expt 3. Effect of size of particles on the retention time in cows

Part $\mathrm{I}$. The results are shown in Table 4 . On average, the mean time of retention of these particles in the alimentary tract was directly related to their diameter. However, occasionally aberrant results were found, e.g. in cow E when given I $5 \mathrm{lb}$ hay, and in cow $\mathrm{C}$.

Part 2. The mean retention times found are shown in Table 5. The results show that size of particles had most effect on mean retention time with particles of $\mathrm{sp}$. gr. I·02.

Table 4. Expt 3, Part I. Effect of size of particle on the mean retention time of particles* of methyl methacrylate in the alimentary tract of the cow

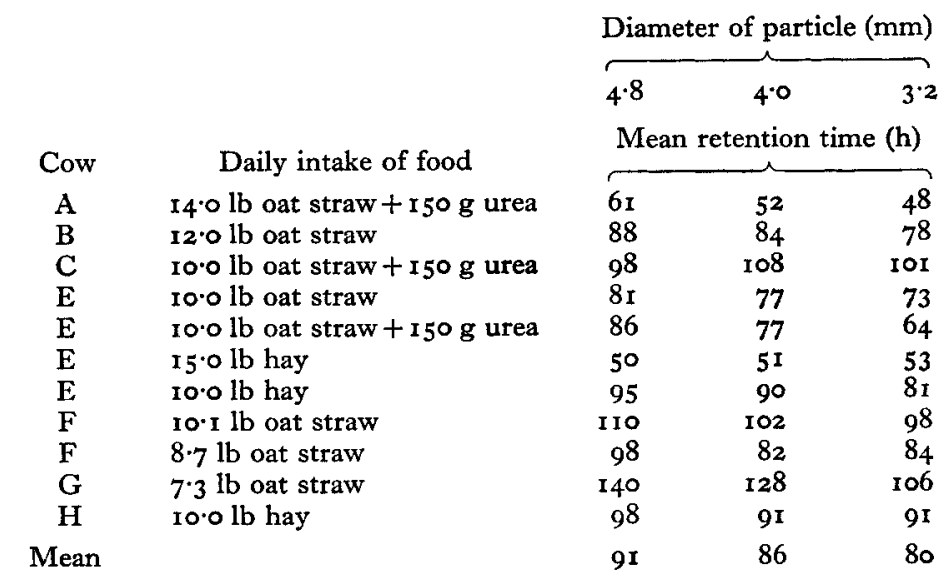

* Placed in rumen.

Table 5. Expt 3, Part 2. Effect of size and specific gravity on the mean retention time of rubber particles* in the alimentary tract of the cow

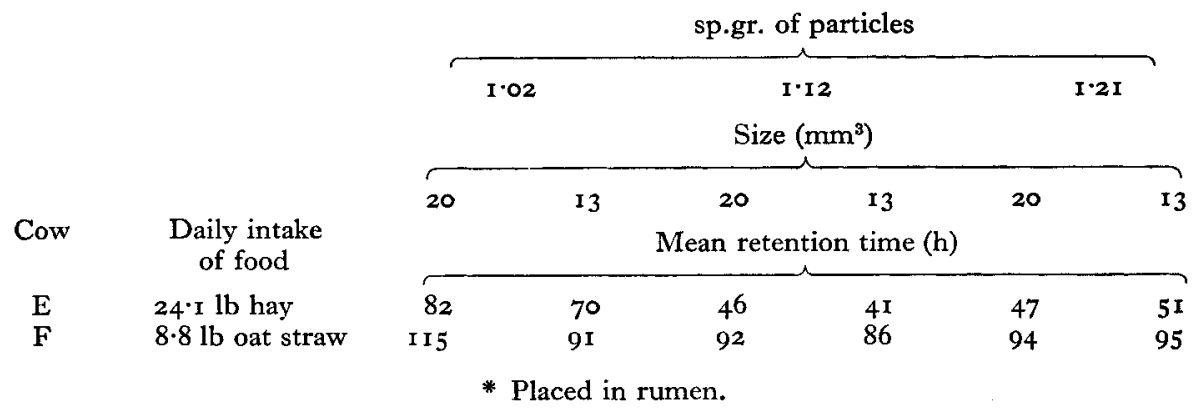

Expt 4. Comparison of the times of retention in cows of polystyrene particles and stained food

The results of this comparison are shown graphically in Fig. 3, in which the mean retention time of polystyrene particles is plotted against that of stained food. The correlation coefficients between the mean retention times of each method were 0.75 for the measurements on cows given hay and 0.79 for cows given oat straw. This 
degree of association is insufficient for the prediction of mean retention time of stained particles from that of polystyrene particles. Errors of about $\pm 6 \%$ in the prediction would be acceptable, but these might be considerably exceeded, as can be seen from the residual standard deviations of the appropriate regression equations, which were $\pm 5.3 \mathrm{~h}$ for hay and $\pm 10 \cdot 4 \mathrm{~h}$ for oat straw. In general, polystyrene particles passed through the tract more rapidly than stained roughage, owing presumably to the

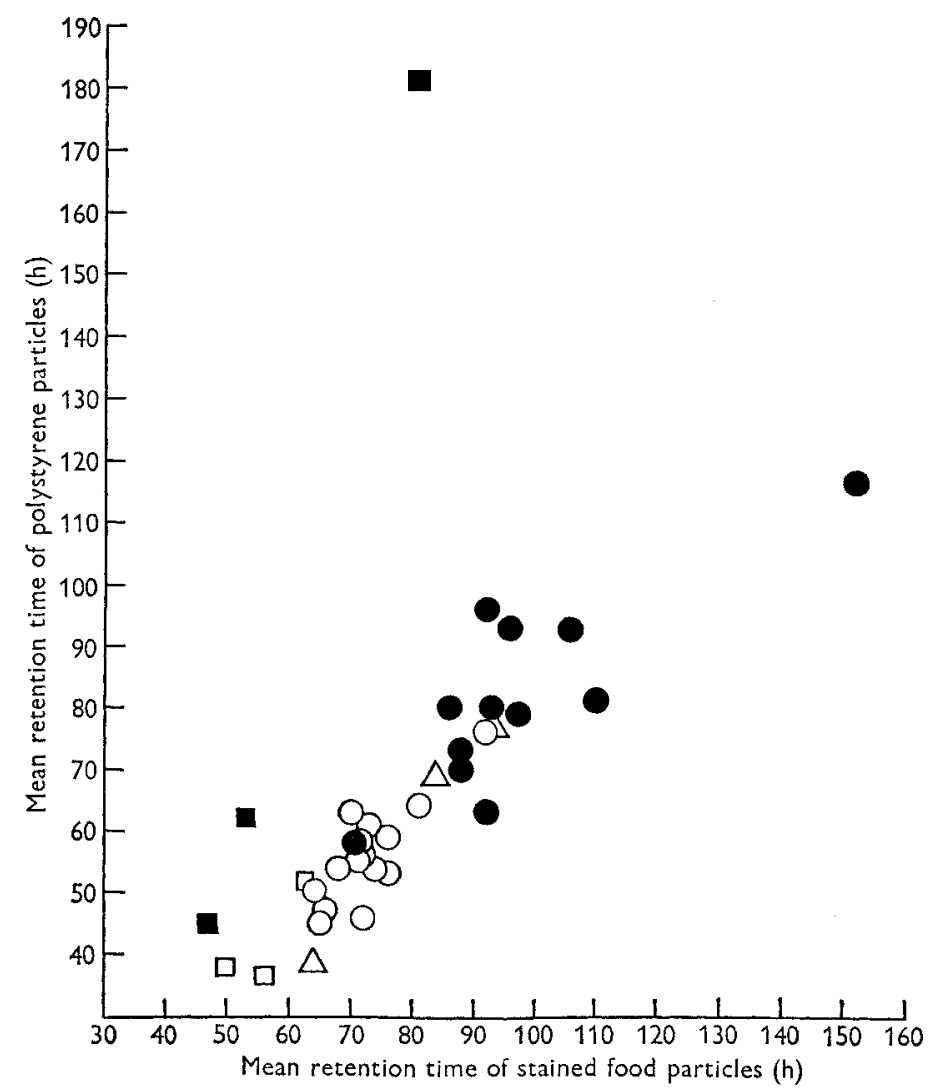

Fig. 3. Expt 4. Relationship between the mean retention times of polystyrene particles and stained food particles in cows receiving hay $(0)$, oat straw $(\bullet)$, oat straw + urea $(\Delta)$, dried grass $(\square)$ or concentrates ( $\boldsymbol{a})$.

additional time required for the breakdown of roughage particles in the reticulo-rumen. In contrast to this observation, polystyrene particles passed more slowly than stained food through the gut of cows given concentrates alone, owing presumably to the high specific gravity of the concentrates.

\section{DISCUSSION}

The results of these experiments show the importance of specific gravity in determining the mean retention time of inert particles in the alimentary tract of the cow. With diets of roughages, particles of sp. gr. $\mathrm{x} \cdot \mathrm{I} 2$ had a shorter mean time of retention in the whole tract than particles of smaller or greater sp. gr. within the range $\mathrm{r} \cdot 02-\mathrm{r} \cdot 40$. 
With a diet of concentrates, particles of sp. gr. $\mathbf{I} \cdot 2 \mathrm{I}$ had the shortest mean retention time. King \& Moore (1957) claimed that with a diet of hay and grain the optimum sp. gr. (for maximum rate of passage) was $\mathrm{I} \cdot 20$. This value was calculated from the percentage of ingested particles recovered in $100 \mathrm{~h}$ and is therefore not strictly comparable with our results which were based on the number of particles recovered in collections up to $300 \mathrm{~h}$. It should be emphasized that the recovery of ingested particles in roo $\mathrm{h}$ depends on the extent to which they are chewed as well as on the time they are retained in the alimentary tract.

It appears that the effect of specific gravity on mean retention time in the whole tract is a combined effect of two factors, each independently related to specific gravity. Firstly the mean retention time in the reticulo-rumen was inversely related to sp. gr. in the range from $\mathrm{I} \cdot 02$ to at least $\mathrm{I} \cdot 2 \mathrm{I}$. Secondly, in the hind gut, the mean retention time was directly related to $\mathrm{sp}$. gr. throughout the range $\mathrm{I} \cdot 02-\mathrm{I} \cdot 40$.

The effect of specific gravity on the mean retention time of particles in the reticulorumen probably results from the rate at which the particles separate from the main mass of digesta, sink to the fluid layer in the ventral rumen and reticulum and so pass to the omasum. This separation appears to lead to faster passage out of the reticulorumen as the sp. gr. increases from I.02 to I.2I. Particles of sp. gr. I.40 appear, however, to be retained almost always in the reticulo-rumen for a longer time than particles of sp. gr. I.21. It is probable that, although particles of sp. gr. I.40 separate rapidly, they are less readily transported in the liquid digesta leaving the reticulo-rumen. More extreme examples of this effect were observed by Dewey, Lee \& Marston (I958). In Expt 2 when plastic particles of sp. gr. 0.95 were placed in the reticulo-rumen and abomasum simultaneously in cows receiving concentrates alone the results indicated that these particles were retained in the reticulo-rumen for a longer time than any of the denser particles used in this experiment. However, despite the absence of rumination with this diet, the recovery of particles of sp. gr. 0.95 was less than $25 \%$ in $300 \mathrm{~h}$, and it was not possible to calculate their mean retention time.

The relationship between the specific gravity of inert particles and their mean retention time in the hind gut probably results from the direct effect of specific gravity on the extent to which particles separate from the main flow of digesta. For transport in the digesta there is probably an optimum sp. gr. of about $\mathrm{I} \cdot 04$ (Balch \& Kelly, 1950), and it would be expected that particles of lower specific gravity would pass very slowly. Results of a few observations with particles of sp. gr. 0.95 confirm this suggestion, although the recovery of these particles was too low to allow calculation of their mean retention time.

The relationship between specific gravity and retention time in the hind gut established by us appears to agree with the results of King \& Moore (1957) for particles in the hind gut of steers and in the alimentary tract of human subjects. Although these authors claimed that a maximum rate of passage was found with particles of sp. gr. $1 \cdot 20$, in fact their results show that particles of sp. gr. $1 \cdot 09$ were retained for a shorter time than particles of sp. gr. I 20 .

In Expt 2 stained food residues from a diet of dried grass passed through the alimentary tract faster than those from a diet of hay. This general pattern was also 
followed by the various inert particles studied in this experiment. With both hay and dried grass a minimum retention time in the whole tract was found with inert particles of sp. gr. I·I2, whereas when concentrates were offered alone the optimum sp. gr. was $\mathrm{I} \cdot \mathbf{2 1}$. In the reticulo-rumen alone particles of sp. gr. $\mathrm{I} \cdot 2 \mathrm{I}$ were retained for the shortest time with diets of hay or dried grass, but a minimum retention time had not so clearly been reached with a diet of concentrates. It is probable that these differences between foods are related to the differences in the specific gravity of digesta derived from each food. Schalk \& Amadon (I928) observed that with mixed diets some of the dense materials such as concentrates quickly fell to the anterior ventral area of the reticulo-rumen and were soon transferred to the hind gut. With dried grass there was very little difference between our cows in the mean retention time of particles of the same specific gravity. With hay the only individual difference was shown by cow $\mathrm{C}$ in which the mean retention time of inert particles in the hind gut was much more dependent on specific gravity than it was in the other two cows. We can offer no explanation for this observation. With concentrates there were very large differences between the cows

Table 6. Expt 2. Relation in the reticulo-rumen between the mean retention time of rubber particles, the digestibility of organic matter, the proportion of digestible organic matter digested and the mean daily weight of organic matter passing through the reticulo-omasal orifice in the three cows receiving concentrates alone

\begin{tabular}{|c|c|c|c|c|}
\hline Cow & $\begin{array}{l}\text { Mean retention time } \\
\text { of particles of } \\
\text { sp. gr. I.2I } \\
\text { (h) }\end{array}$ & $\begin{array}{c}\text { Digestibility of } \\
\text { organic matter } \\
(\%)\end{array}$ & $\begin{array}{l}\text { Proportion of total } \\
\text { digestible organic } \\
\text { matter digested } \\
(\%)\end{array}$ & $\begin{array}{l}\text { Mean daily weight of } \\
\text { organic matter trans- } \\
\text { ferred to omasum } \\
\text { (lb) }\end{array}$ \\
\hline $\mathrm{A}$ & I8 & $38 \cdot 1$ & $47 \cdot 3$ & IO.I \\
\hline B & Iro & $62 \cdot 3$ & 74.6 & $5 \cdot 6$ \\
\hline C & 9 & $15 \%$ & 18.2 & 12.0 \\
\hline
\end{tabular}

in the mean retention time of inert particles in the reticulo-rumen. As shown in Table 6 these individual times of retention for particles of sp. gr. I.2I (which were retained for the shortest time in the reticulo-rumen) were directly related to the digestibility of organic matter in the reticulo-rumen and inversely related to the mean amount of organic matter transferred daily from the reticulo-rumen to the omasum. The percentage disappearance of organic matter by digestion was estimated by a lignin-ratio technique (Balch, 1957) and is subject to the reservations made by him. This estimate was used to calculate the daily weight of organic matter passing through the reticulo-omasal orifice. It is hoped that fuller details of these estimates will be published in a subsequent paper.

The mean retention time of inert particles of $\mathrm{sp}$. gr. $\mathrm{I} \cdot 20$ was directly related to the size of particles within the range $17-58 \mathrm{~mm}^{3}$. The largest particles were found to be retained on average for $12 \%$ more time than the smallest. It may be of importance that the relationship between the diameter of the particle and mean retention time appears to be almost linear. Within this range $\left(17-58 \mathrm{~mm}^{3}\right)$ our results show a considerably greater effect of particle size on mean retention time than those of King \& Moore (1957). These workers also suggest that the mean retention time of particles below $17 \mathrm{~mm}^{3}$ is inversely related to size. However, in their experiment, particles below $17 \mathrm{~mm}^{3}$ 
reached this size an unknown time after ingestion, through the process of rumination; the rate of recovery of such particles cannot be used, therefore, to give an accurate measure of the time of retention of particles of this size.

\section{SUMMARY}

I. In four experiments with five Shorthorn and two Friesian cows the effect of specific gravity and size on the mean retention time of particles of rubber and plastics in the alimentary tract has been examined.

2. In two experiments rubber particles of similar size $\left(13 \mathrm{~mm}^{3}\right)$ and of different sp. gr., I.04, I.06, I.I2, I.2I and I.40, were introduced simultaneously into the reticulum and abomasum of cows receiving diets of hay, oat straw, dried grass or dairy cubes. The mean retention time of particles in the reticulo-rumen was inversely related to their $\mathrm{sp}$. gr. within the range $\mathrm{I} \cdot 02-\mathrm{I} \cdot 2 \mathrm{I}$. Particles of $\mathrm{sp}$. gr. I·40 were retained for a longer time in the reticulo-rumen than those of $\mathrm{sp}$. gr. I.2I. In the hind gut the mean time of retention of particles was directly related to sp. gr. within the range $\mathrm{I} \cdot \mathrm{O} 2-\mathrm{I} \cdot \mathbf{4}^{\circ}$.

3. The effect of particle size on the mean retention time was examined in Expt 3 , with methyl methacrylate particles (sp. gr. $1 \cdot 2$ ), $4^{\cdot 8}, 4^{\cdot 0}$ and $3 \cdot 2 \mathrm{~mm}$ in diameter. Within this range the mean retention time was directly related to the size of the particle.

4. A comparison of the mean retention times of polystyrene particles (sp. gr. 1・04) and stained food was made on thirty-six occasions, and correlation coefficients of about 0.8 were found between the values determined by each method. It was concluded that polystyrene particles were unlikely to provide an alternative method of estimating the mean retention time of stained food in the alimentary tract of the cow.

5. The results are discussed in relation to the function of the reticulo-rumen, particularly the passage of food through this organ and the extent of digestion in the reticulo-rumen.

We thank Dr C. C. Balch for help and advice during these experiments. One of us (M.F.) thanks the University of Melbourne and the Australian Dairy Produce Board for financial assistance.

\section{REFERENCES}

Balch, C. C. (1950). Brit. F. Nutr. 4, 36r.

Balch, C. C. (1957). Brit. F. Nutr. I1, 213.

Balch, C. C., Bartlett, S. \& Johnson, V. W. (195I). F. agric. Sci. 4I, 98.

Balch, C. C. \& Kelly, A. (1950). Brit. F. Nutr. 4, 395.

Campling, R. C. \& Freer, M. (1960). Nature, Lond., 188, 670.

Campling, R. C., Freer, M. \& Balch, C. C. (1961). Brit. F. Nutr. 15, 53 I.

Castle, E. J. (1956). Brit. F. Nutr. ro, 15.

Dewey, D. W., Lee, H. J. \& Marston, H. R. (1958). Nature, Lond., 181, 1367.

Ewing, P. V. \& Smith, F. H. (1917). F. agric. Res. ro, 55.

Hoelzel, F. (1930). Amer. F. Physiol. 92, 466.

King, K. W. \& Moore, W. E. C. (1957). F. Dairy Sci. 40, 528.

Moore, L. A. \& Winter, O. B. (1934). F. Dairy Sci. 17, 297.

Schalk, A. F. \& Amadon, R. S. (1928). Bull. N. Dak. agric. Exp. Sta. no. 2 I6.

\section{Printed in Great Britain}

